\title{
Adjuvant Radiation for Rectal Cancer: Do We Measure Up to the Standard of Care? An Epidemiologic Analysis of Trends Over 25 Years in the United States
}

\author{
N. N. Baxter, M.D., Ph.D., ${ }^{1}$ D. A. Rothenberger, M.D., ${ }^{1}$ A. M. Morris, M.D., M.P.H., ${ }^{2}$ \\ K. M. Bullard, M.D. ${ }^{1}$ \\ ${ }^{1}$ Division of Colon and Rectal Surgery, Department of Surgery, University of Minnesota, \\ Minneapolis, Minnesota \\ ${ }^{2}$ Division of Colon and Rectal Surgery, Department of Surgery, University of Michigan, \\ Ann Arbor, Michigan
}

PURPOSE: In the United States, adjuvant radiation therapy is currently recommended for most patients with rectal cancer. We conducted this population-based study to evaluate the rate of radiation therapy and the factors affecting its delivery. METHODS: We used the Surveillance Epidemiology and End Results database to assess treatment of patients with nonmetastatic rectal cancer diagnosed over a 25 -year period (1976 through 2000). We evaluated the rate of radiation therapy use and its timing (preoperative $v s$. postoperative) and the influence of factors such as tumor stage and grade; patient gender and race; and geographic location. RESULTS: In this 25 -year period, 45,627 patients met our selection criteria. The rate of radiation therapy use increased dramatically over time: from 17 percent of advanced-stage patients in 1976 to 65 percent in 2000 ( $P<$ $0.0001)$. Until 1996, the increase was due almost entirely to postoperative radiation therapy. Since 1996 , the rate of pre-

Supported in part by the University of Minnesota Cancer Center.

Read at the meeting of The American Society of Colon and Rectal Surgeons, Dallas, Texas, May 8 to 13, 2004.

Reprints are not available.

Correspondence to: N. N. Baxter, M.D., Ph.D., Division of Surgical Oncology, Department of Surgery, University of Minnesota, 420 Delaware Street SE, MMC 450, Minneapolis, Minnesota 55455, e-mail: baxte025@umn.edu

Dis Colon Rectum 2005; 48: 9-15

DOI: $10.1007 / \mathrm{s} 10350-004-0792-8$

(c) The American Society of Colon and Rectal Surgeons

Published online: 7 December 2004 operative radiation therapy use has increased $(P<0.0001)$ and the rate of postoperative radiation therapy use has begun to decline. We found, after controlling for the year of diagnosis, that female patients, African Americans, older patients, and patients with low-grade lesions were less likely to undergo radiation therapy $(P<0.0001)$. Geographic location was also an important predictor of radiation therapy use. CONCLUSIONS: The use of radiation therapy for patients with rectal cancer has dramatically increased over the 25-year period studied, with a recent shift to the use of preoperative radiation therapy; however, in 2000, over 30 percent of patients with advanced-stage nonmetastatic rectal cancer did not undergo radiation therapy. Given the variation in radiation therapy use that we found to be due to demographic factors, access to adjuvant radiation therapy can be improved. [Key words: Rectal cancer; Adjuvant radiation; Patterns of care; Staging; Preoperative radiation]

$\mathrm{R}$ ectal cancer, a common cancer, is associated with significant morbidity and mortality. In 2004, almost 41,000 Americans will develop rectal cancer. ${ }^{1}$ The traditional treatment of this disease has relied on radical resection. Unfortunately, in the past, such patients experienced significant rates of local recurrence. Reported rates of local recurrence were as high as 30 percent, ${ }^{2}$ with a median local recurrence rate of 18.5 percent. ${ }^{3}$ Local recurrence is a multifactorial problem and is affected by tumor, patient, and treat- 
ment factors. The high rates of recurrence led to efforts to improve local tumor control. Standardization of the surgical approach, including meticulous dissection of the mesorectum (total mesorectal excision), significantly reduced local recurrence after radical excision of rectal cancer in many centers. ${ }^{4,5}$ Nonetheless, local recurrence remains a problem.

In 1990, the National Institutes of Health (NIH) Consensus Conference established adjuvant postoperative radiation therapy, along with chemotherapy, as the standard of care for achieving regional control of Stage II and III rectal cancer after surgical resection in the United States. ${ }^{6}$ Numerous studies have substantiated the benefits of adjuvant radiation therapy for preventing local recurrence in patients with rectal cancer. $^{7-10}$ However, we do not know the rate of radiation therapy use in patients with rectal cancer, or the timing of radiation therapy (preoperative $v s$. postoperative). Most previous assessments of the rate of radiation therapy use have included only individuals age 65 and older, ${ }^{11,12}$ have included only small numbers of patients, ${ }^{13}$ or have not been population based $^{14}$; only one such study evaluated trends over time. $^{14}$

The aim of our population-based study was to evaluate U.S. trends in adjuvant radiation therapy use over a 25-year period, timing (preoperative $v s$. postoperative) of radiation therapy, and factors affecting radiation delivery.

\section{MATERIALS AND METHODS}

\section{Data}

We used data from the Surveillance Epidemiology and End Results (SEER) cancer registry to conduct this study. SEER, a population-based registry sponsored by the National Cancer Institute, collects information on cancer incidence and survival from 11 populationbased cancer registries and 3 supplemental registries; these 14 registries include approximately 14 percent of the U.S. population. ${ }^{12}$ Two of the 11 registries were added in 1992. The information collected by SEER includes patient characteristics, county of residence, primary tumor site, tumor grade, and stage at diagnosis. Although formal American Joint Committee on Cancer (AJCC) staging information has only been available in SEER since 1988, SEER has coded disease as localized, regional, or metastatic since its inception. Regional disease is described as having direct extension into adjacent organs or involvement of regional lymph nodes, and thus would include some AJCC Stage II lesions (T4NO) and AJCC Stage III lesions. Other information collected by SEER includes first course of treatment (through completion of the initial treatment plan, including treatment within the first year after diagnosis or until there is evidence, within the first year, either of disease progression or of treatment failure), radiation sequence with respect to surgery, and follow-up for vital status. ${ }^{12}$ SEER does not collect information regarding administration of chemotherapy.

\section{Patients}

We included patients age 18 or older who were diagnosed with adenocarcinoma of the rectum from January 1976 through December 2000. Excluded from our study were patients who had in situ or metastatic disease, patients with malignancies other than adenocarcinoma, and patients who did not undergo some form of surgical therapy.

\section{Analysis}

We determined the overall rate of radiation, preoperative radiation, and postoperative radiation. We evaluated the effect of demographic, surgical, and tumor factors on radiation and determined time trends. We compared means using the Wilcoxon rank-sum test and proportions using the chi-squared test. We used the Cochran-Armitage trend test on one degree of freedom to determine whether rates had changed over time. We used logistic regression to test the associations between radiation and age, race, gender, year of diagnosis, tumor grade, tumor stage, surgical treatment, and geographic location by registry. We limited the logistic regression to patients diagnosed from 1988 through 2000, such that only patients with available AJCC staging were included. Our analysis was limited to patients for whom radiation is routinely recommended (AJCC Stage II and III patients).

Our study used preexisting data with no personal identifiers, and was thus exempt from review by the University of Minnesota's Institutional Review Board.

\section{RESULTS}

A total of 45,627 patients in our 25-year study period were diagnosed with rectal cancer and met our selection criteria. In 99 percent of these patients ( $\mathrm{n}=$ $45,000)$, radiation status could be determined. Of 
Table 1.

Demographic Characteristics of All Study Patients

\begin{tabular}{lccc}
\hline & $\begin{array}{c}\text { All Patients } \\
(\mathrm{n}=45,627)\end{array}$ & $\begin{array}{c}\text { Radiation Therapy Use } \\
(\mathrm{N}=14,571(32 \%))\end{array}$ & $\begin{array}{c}\text { No Radiation Therapy Use } \\
(\mathrm{N}=30,429(68 \%))\end{array}$ \\
\hline $\begin{array}{l}\text { Age in years (median) } \\
\text { Male:female ratio (\%) }\end{array}$ & 68 & 65 & 70 \\
Race & $57: 43$ & $61: 39$ & $55: 45$ \\
$\quad$ Non-African American & $42,965(94 \%)$ & $13,670(94 \%)$ & $28,728(95 \%)$ \\
African American & $2,545(6 \%)$ & $888(6 \%)$ & $1,599(5 \%)$ \\
SEER stage & $24,992(54.7 \%)$ & $4,267(29 \%)$ & $20,528(67 \%)$ \\
Localized spread & $18,559(40.6 \%)$ & $9,351(64 \%)$ & $8,809(29 \%)$ \\
Regional spread & $2,076(4.5 \%)$ & $953(7 \%)$ & $1,092(4 \%)$ \\
Unknown & & & $6,181(85 \%)$ \\
Year of diagnosis & 7,342 & $1,093(15 \%)$ & $6,038(75 \%)$ \\
1976-1980 & 8,188 & $2,054(25 \%)$ & $5,377(67 \%)$ \\
1981-1985 & 8,177 & $2,708(33 \%)$ & $6,057(62 \%)$ \\
1986-1990 & 9,990 & $3,747(38 \%)$ & $6,776(58 \%)$ \\
1991-1995 & 11,930 & $4,969(42 \%)$ & $4,480(15 \%)$ \\
1996-2000 & & $1,166(8 \%)$ & $16,506(54 \%)$ \\
Grade & $5,706(13 \%)$ & $9,095(62 \%)$ & $3,094(10 \%)$ \\
Well differentiated & $25,982(57 \%)$ & $2,776(19 \%)$ & $6,349(21 \%)$ \\
Moderately differentiated & $5,980(13 \%)$ & $1,534(11 \%)$ & $73 \%$ \\
Poorly differentiated & $7,959(17 \%)$ & $90 \%$ & \\
Unknown & $79 \%$ & & \\
Radical resection (\%) & & & \\
\hline
\end{tabular}

SEER = Surveillance Epidemiology and End Results.

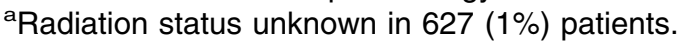

${ }^{\mathrm{b}}$ Race information missing for 117 patients $(<1 \%)$.

'Surgery information available since 1983.

these patients 14,571 (32 percent) underwent radiation therapy (Table 1). Patients who underwent radiation therapy tended to be younger (median age, 65) than those who did not undergo radiation therapy (median age, 70$)(P<0.0001)$. They were more likely to be male (61 percent male, radiation therapy, vs. 55 percent male, no radiation therapy; $P<0.0001)$. Patients who underwent radiation therapy were also more likely to have regional spread (64 percent) than those who did not undergo radiation therapy (29 percent $)(P<0.0001)$. In addition, patients who underwent radiation therapy were more likely to have also undergone radical excision as part of treatment $(90$ percent) than those who did not undergo radiation therapy $(73$ percent $)(P<0.0001)$. Of note, detailed surgical information has only been available in SEER since 1983. Before adjustment for other factors, African Americans were slightly more likely to receive radiation (35 percent) than non-African Americans (32 percent) $(P<0.0003)$. However African Americans were also more likely to have regional disease ( 47 percent of those with known stage) than non-African Americans ( 42 percent of those with known stage) $(P<0.00001)$.

The frequency of radiation therapy use for patients with rectal cancer substantially increased over our study time period: 12 percent of such patients underwent radiation therapy in 1976 vs. 42 percent in 2000 $(P<0.0001$; Fig. 1). For patients with regional spread, the increase was even more dramatic: from 17 percent in 1976 to 65 percent in 2000. Of those with regional spread who underwent radical excision, 41 percent underwent radiation therapy in 1983 vs. 65 percent in 2000 ( $P<0.0001 ;$ Fig. 1). No dramatic change in the rate of increase of radiation therapy use has occurred in the years following 1990 (the year of the NIH Consensus Conference statement recommending adjuvant radiation therapy for AJCC Stage II and III rectal cancer). For AJCC Stage II patients, the rate of radiation therapy use in 2000 was 59 percent; for Stage III patients it was 68 percent.

The increase in radiation therapy use was due almost entirely to postoperative radiation therapy use until 1996. Since that time, the rate of preoperative radiation therapy use has significantly increased $(P<$ $0.0001)$ and the rate of postoperative radiation has actually begun to decline (Fig. 2). Of note, we found significant staging differences for patients who underwent preoperative radiation $v s$. those who underwent postoperative radiation. Patients who underwent pre- 


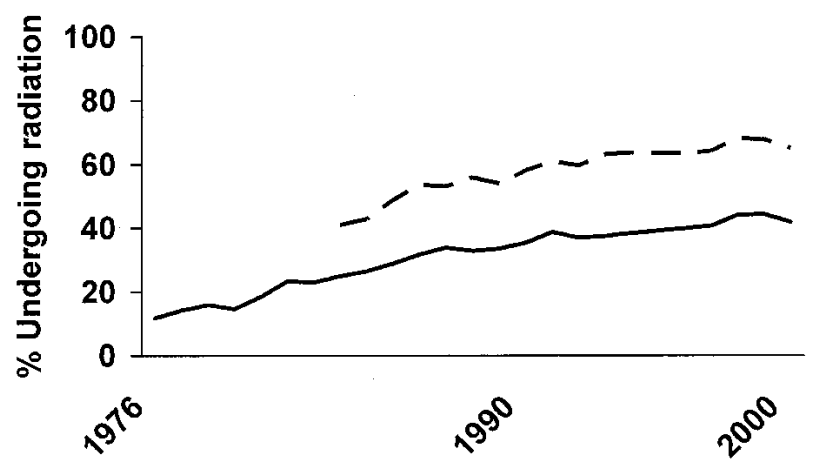

Year of Diagnosis

Figure 1. Proportion of all patients diagnosed with rectal cancer who underwent radiation therapy over time. Solid line = proportion of patients undergoing radiation therapy, all patients; dashed line = proportion of patients undergoing radiation therapy, of those with regional spread who underwent radical resection. Information on extent of surgical resection was available only from 1983.

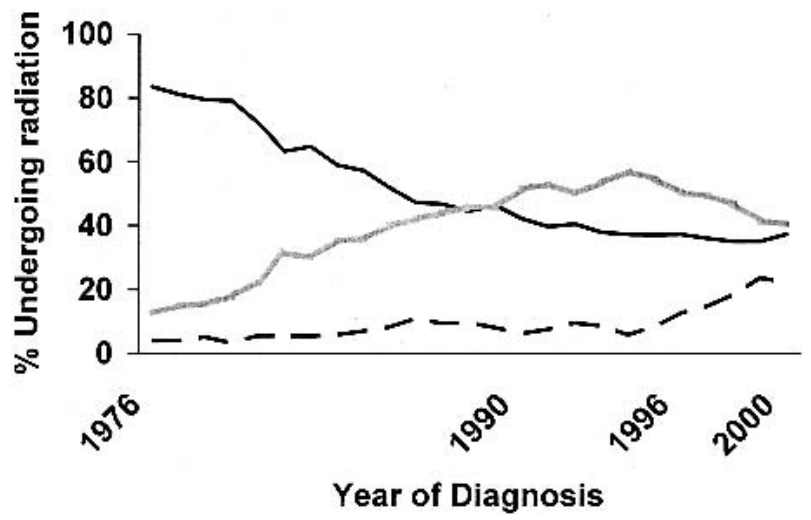

Figure 2. Proportion of patients with regional spread who underwent radiation therapy over time. Solid line $=$ proportion of patients with regional spread who did not undergo radiation therapy; dashed line = proportion of patients with regional spread who underwent preoperative radiation therapy; gray line $=$ proportion of patients with regional spread who underwent postoperative radiation therapy.

operative ( $v s$. postoperative) radiation were more likely to be missing stage information (18 percent $v s$. 2 percent; $P<0.0001)$; they were also more likely to have localized disease (38 percent $v$ s. 26 percent; $P<$ 0.0001). Conversely, patients who underwent preoperative ( $v s$. postoperative) radiation were less likely to have regional spread ( 44 percent $v$ s. 72 percent; $P<$ 0.0001).

In our multivariate models, controlling for the year of diagnosis and geographic location by registry, we found that male gender and younger age were predictors of radiation therapy use $(P<0.0001)$ (Table 2$)$.
African Americans were less likely to undergo radiation therapy $(P<0.003)$ than patients of other races. Patients with poorly differentiated rectal cancer and those with AJCC Stage III rectal cancer were significantly more likely to undergo radiation therapy than those with well-differentiated or moderately differentiated rectal cancer or with AJCC Stage II cancer $(P<$ 0.0001). In all our multivariate models, the year of diagnosis and geographic location by registry remained important predictors of radiation therapy $(P<$ 0.0001).

\section{DISCUSSION}

Our study demonstrates a gradual but persistent increase in adjuvant radiation therapy use for patients with rectal cancer over a 25-year period: from 17 percent in 1976 to 65 percent in 2000 for patients with regional spread. Interestingly, despite the NIH Consensus Conference recommendations in 1990, the rate of radiation therapy use did not dramatically rise after that recommendation. Thus the increase was not in direct response to it. In terms of AJCC staging (available in SEER only since 1988), we found that the rate of radiation therapy use in 2000 was 59 percent for AJCC Stage II patients and 68 percent for AJCC Stage III patients. Although most patients underwent appropriate adjuvant radiation therapy, substantial numbers of patients who might benefit from therapy did not receive it-perhaps more than 7,000 patients in the United States per year (extrapolating from our data to the U.S. population). In many cases, patients may not have undergone radiation therapy because of appropriate medical considerations (e.g., extreme medical comorbidity) or because of their own preference. However, given the variations in adjuvant radiation therapy use that we identified with regard to age, race, gender, and geographic location, and given the considerable change in the rate over time, it is likely that other modifiable factors_-such as the underlying practice patterns of individual surgeons or institutions-played an important role.

The overall rate of adjuvant radiation therapy use that we found in 2000 for AJCC Stage II (59 percent) and Stage III patients (68 percent) appears to be higher than the rate found in other population-based studies. Two previous studies used SEER data linked to Medicare data to examine the rate of adjuvant radiation and chemotherapy use in individuals age 65 and older from 1992 through 1996. One of these stud- 
Table 2.

Factors Influencing Radiation Therapy Use in AJCC Stage II and Stage III Patients ${ }^{\text {a }}$

\begin{tabular}{|c|c|c|}
\hline & $\begin{array}{l}\text { Odds Ratio for } \\
\text { Radiation Therapy Use }\end{array}$ & $\begin{array}{l}95 \% \text { Confidence Interval } \\
\text { for Odds Ratio }\end{array}$ \\
\hline \multicolumn{3}{|l|}{ Age at diagnosis ${ }^{b}$} \\
\hline$>70$ years & 1 & Reference group \\
\hline$<65$ to $\leq 70$ years & 3.03 & $2.76-3.33$ \\
\hline$\leq 60$ years & 4.95 & $4.48-5.46$ \\
\hline \multicolumn{3}{|l|}{ Gender $^{\mathrm{b}}$} \\
\hline Male & 1 & Reference group \\
\hline Female & 0.81 & $0.75-0.88$ \\
\hline \multicolumn{3}{|l|}{ Race $^{\mathrm{c}}$} \\
\hline Non-African American & 1 & Reference group \\
\hline African American & 0.77 & $0.65-0.92$ \\
\hline \multicolumn{3}{|l|}{ AJCC tumor stage ${ }^{\mathrm{b}}$} \\
\hline AJCC II & 1 & Reference group \\
\hline AJCC III & 1.76 & $1.62-1.90$ \\
\hline \multicolumn{3}{|l|}{ Grade $^{\mathrm{b}}$} \\
\hline Poorly differentiated & 1 & Reference group \\
\hline Moderately differentiated & 0.79 & $0.72-0.88$ \\
\hline Well differentiated & 0.71 & $0.60-0.85$ \\
\hline \multicolumn{3}{|l|}{ Type of surgery ${ }^{d}$} \\
\hline Local & 1 & Reference group \\
\hline Radical & 1.34 & $1.01-1.79$ \\
\hline \multicolumn{3}{|c|}{$\begin{array}{l}\text { ancludes patients since 1988, adjusted for geographic location by registry and by year of diagnosis. AJCC }=\mathrm{A} \\
\text { oint Committee on Cancer. }\end{array}$} \\
\hline
\end{tabular}

ies found a rate of radiation use of 51 percent $^{12}$; the other, 57 percent. ${ }^{11}$ Both focused on AJCC Stage II and III patients. But given the influence of older age on radiation therapy use that numerous studies ${ }^{11-13}$ (including ours) have noted, those two studies of individuals age 65 and older do not apply to younger patients. In a similar study evaluating 534 adult patients who developed rectal cancer in 1996 and 1997 while residing in California Cancer Registry regions, the unadjusted rates of adjuvant radiation varied from 82 percent in patients younger than 55 years old to 14 percent in patients at least 85 years of age. It is noteworthy that none of the population-based studies evaluated trends over time. None of the previous studies evaluated trends in preoperative delivery of adjuvant radiation.

The National Cancer Data Base $(\mathrm{NCDB})^{14}$ reported trends in rectal cancer treatment over time, comparing treatment in 1985-86, 1989-90, and 1994-95. A much smaller change in the use of adjuvant radiation was seen in this NCDB report: adjuvant radiation therapy use increased from 54 percent in AJCC Stage III patients in the first years studied to 61 percent in the final years studied. The NCDB study was not population based, and its findings in 1994-95 may not be directly comparable to the earlier time periods; the proportion of rectal cancer patients in the United States included in the NCDB increased from 24 percent of all patients in 1985-86 to 53 percent in 199495. Hospitals reporting data in the first years of the NCDB study likely had substantially different treatment practices, compared with hospitals recruited to the NCDB in subsequent years or compared with all hospitals in the United States. In addition, the NCDB study did not look at trends in preoperative radiation therapy.

Consistent with growing evidence of the effectiveness and superiority of preoperative radiation, ${ }^{7-9,15,16}$ our study demonstrates a substantial increase in its use since 1996. In fact, although the overall rate of any adjuvant radiation has continued to increase, since 1996 the rate of postoperative radiation has actually declined. In our study, we noted important differences in staging between patients who underwent preoperative radiation. Patients who underwent preoperative $v s$. postoperative radiation were more likely to be missing staging information or to have earlystage disease. We are not able to determine whether those differences were caused by a complete pathologic tumor response (which occurs in 10 percent to 
20 percent of rectal cancer patients who undergo preoperative chemoradiation therapy $)^{17-20}$; by downstaging because of partial tumor response after radiation; by uncertainty on the part of the person doing the staging as to how to interpret AJCC rules after preoperative therapy; by inadequate nodal evaluation; or by other factors. However, given the increasing rate of preoperative radiation therapy use, researchers using the SEER database in the future must carefully consider its influence on stage distribution in SEER. In fact, because of the effect of preoperative radiation on staging and the increasing frequency in the use of preoperative radiation, stage-specific research using SEER may be difficult or impossible.

Our population-based study included large numbers of patients. Yet only limited information on patient and tumor characteristics is available from SEER. Such characteristics, of course, may affect treatment decisions, but we could not control for them in our study. Of note, SEER does not include information on administration of chemotherapy, so we could not evaluate the use of adjuvant chemotherapy in combination with radiation. Because the formal AJCC stage is only available in SEER as of 1988, we could not evaluate radiation trends with regard to AJCC stage for our entire study period. Still, in the final year of our study the rates of adjuvant radiation use were similar in patients with regional spread per SEER (65 percent) and those with AJCC Stage III disease (68 percent). This finding, we believe, justifies our use of SEER staging to evaluate trends.

Despite these limitations, our study demonstrated a dramatic increase in adjuvant radiation use for rectal cancer patients over time and also demonstrated a recent shift from postoperative to preoperative adjuvant radiation therapy. However, even in the final year of our study, we noted that significant numbers of patients who might have benefited from radiation did not undergo it. Given the variations in adjuvant radiation therapy use by patient age at diagnosis, gender, race, and geographic location identified in our study and in others, ${ }^{11-13,21}$ access to this beneficial and recommended therapy can still be improved. Continued study of treatment trends and of factors influencing them is needed.

\section{ACKNOWLEDGMENT}

The authors thank Dr. Mary Knatterud for her helpful editorial comments.

\section{REFERENCES}

1. American Cancer Society. Cancer facts and figures, 2004 http://www.cancer.org/downloads/STT/ CAFF_finalPWSecured.pdf Accessed March 25, 2004.

2. Wiig JN, Carlsen E, Soreide O. Mesorectal excision for rectal cancer: a view from Europe. Semin Surg Oncol 1998;15:78-86.

3. McCall JL, Cox MR, Wattchow DA. Analysis of local recurrence rates after surgery alone for rectal cancer. Int J Colorectal Dis 1995;10:126-32.

4. Kockerling F, Reymond MA, Altendorf-Hofmann A, Dworak $\mathrm{O}$, Hohenberger W. Influence of surgery on metachronous distant metastases and survival in rectal cancer. J Clin Oncol 1998;16:324-9.

5. Martling AL, Holm T, Rutqvist LE, Moran BJ, Heald RJ, Cedemark B. Effect of a surgical training programme on outcome of rectal cancer in the County of Stockholm. Stockholm Colorectal Cancer Study Group, Basingstoke Bowel Cancer Research Project. Lancet 2000;356:93-6.

6. NIH Consensus Conference. Adjuvant therapy for patients with colon and rectal cancer. JAMA 1990;264: 1444-50.

7. Anonymous. Improved survival with preoperative radiotherapy in resectable rectal cancer. Swedish Rectal Cancer Trial. N Engl J Med 1997;336:980-7.

8. Kapiteijn E, Marijnen CA, Nagtegaal ID, et al. Dutch Colorectal Cancer Group. Preoperative radiotherapy combined with total mesorectal excision for resectable rectal cancer. N Engl J Med 2001;345:638-46.

9. Colorectal Cancer Collaborative Group. Adjuvant radiotherapy for rectal cancer: a systematic overview of 8,507 patients from 22 randomised trials. Lancet 2001;358: 1291-304.

10. Wolmark N, Wieand HS, Hyams DM, et al. Randomized trial of postoperative adjuvant chemotherapy with or without radiotherapy for carcinoma of the rectum: National Surgical Adjuvant Breast and Bowel Project Protocol R-02. J Natl Cancer Inst 2000;92:388-96.

11. Schrag D, Gelfand SE, Bach PB, Guillem J, Minsky BD, Begg CB. Who gets adjuvant treatment for stage II and III rectal cancer? Insight from surveillance, epidemiology, and end results-Medicare. J Clin Oncol 2001;19: 3712-8.

12. Neugut AI, Fleischauer AT, Sundararajan V, et al. Use of adjuvant chemotherapy and radiation therapy for rectal cancer among the elderly: a population-based study. J Clin Oncol 2002;20:2643-50.

13. Ayanian JZ, Zaslavsky AM, Fuchs CS, et al. Use of adjuvant chemotherapy and radiation therapy for colorectal cancer in a population-based cohort. J Clin Oncol 2003;21:1293-300.

14. Jessup JM, Stewart AK, Menck HR. The National Cancer Data Base report on patterns of care for adenocarcinoma of the rectum, 1985-95. Cancer 1998;83:2408-18. 
15. Camma C, Giunta M, Fiorica F, Pagliaro L, Craxi A, Cottone $\mathrm{M}$. Preoperative radiotherapy for resectable rectal cancer: a meta-analysis. JAMA 2000;284:1008-15.

16. Sauer R. Adjuvant versus neoadjuvant combined modality treatment for locally advanced rectal cancer: first results of the German rectal cancer study (CAO/ARO/ AIO-94). Int J Radiat Oncol Biol Phys 2003;57:S124-5.

17. Reerink O, Verschueren RC, Szabo BG, Hospers GA, Mulder NH. A favourable pathological stage after neoadjuvant radiochemotherapy in patients with initially irresectable rectal cancer correlates with a favourable prognosis. Eur J Cancer 2003;39:192-5.

18. Uzcudun AE, Batlle JF, Velasco JC, et al. Efficacy of preoperative radiation therapy for resectable rectal adenocarcinoma when combined with oral tegafur-uracil modulated with leucovorin: results from a phase II study. Dis Colon Rectum 2002;45:1349-58.

19. Garcia-Aguilar J, Hernandez de Anda E, Sirivongs P, Lee $\mathrm{SH}$, Madoff RD, Rothenberger DA. A pathologic complete response to preoperative chemoradiation is associated with lower local recurrence and improved survival in rectal cancer patients treated by mesorectal excision. Dis Colon Rectum 2003;46:298-304.

20. Luppi G, Santantonio M, Bertolini F, et al. Preoperative concomitant radiotherapy and chemotherapy in ultrasound-staged T3 and T4 rectal cancer. Tumori 2003;89: 152-6.

21. Morris AM, Billingsley KG, Baxter NN, Baldwin LM. Racial disparities in rectal cancer treatment: a populationbased analysis. Arch Surg 2004;139:151-5. 